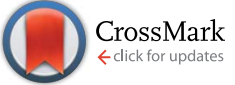

Cite this: RSC Adv., 2017, 7, 4024

\title{
A low-cost and water resistant biomass adhesive derived from the hydrolysate of leather waste $\uparrow$
}

\begin{abstract}
Jianfei Zhou, ${ }^{\text {ab }}$ Teng Xu, $\dot{t}^{\mathrm{b}}$ Xiaoling Wang, ${ }^{\mathrm{a}}$ Chang Liu, ${ }^{a}$ Xuepin Liao, ${ }^{\text {ab }}$ Xin Huang ${ }^{\text {ab }}$ and $\mathrm{Bi} \mathrm{Shib}$

A low-cost and water resistant biomass adhesive, collagen hydrolysate-silane coupling agent hybrids $(\mathrm{CSH})$, was prepared by using collagen hydrolysate $(\mathrm{CH})$ extracted from leather waste as the starting material, and silane coupling agent (SCA) as the crosslinking agent. The as-prepared adhesive was fully characterized by Fourier transform infrared spectroscopy (FTIR), ${ }^{29} \mathrm{Si}$ CP-MAS NMR spectroscopy, differential scanning calorimetry (DSC), scanning electron microscopy (SEM), ANS assay and ninhydrin assay. The as-prepared CSH exhibited pretty good adhesive strength and water resistance. Moreover, the water resistance of $\mathrm{CSH}$ can be conveniently tuned by changing the type and dosage of the silane coupling agent. When used as a wood adhesive, the dry adhesive strength of CSH was as high as $1.57 \mathrm{MPa}$, and the corresponding wet adhesive strength reached $0.95 \mathrm{MPa}$. Our experimental results suggest that the collagen hydrolysate extracted from leather waste has a great potential to be used as a low-cost and highly effective adhesive in the wood composite industry.
\end{abstract}

Received 22nd November 2016 Accepted 28th December 2016

DOI: 10.1039/c6ra27132d

www.rsc.org/advances develop other alternatives, particularly the renewable biomass-based adhesives. ${ }^{6}$ The utilizations of renewable biomass for preparing low-cost adhesives have received considerable attentions over the past decades, and the already investigated biomaterials include, soy protein, ${ }^{7} \operatorname{tannin},{ }^{8}$ and lignin, ${ }^{9}$ etc. As we discussed above, the leather wastes mainly consist of collagen proteins, which account for $\sim 90 \%$ weight of leather wastes. In principle, the polar groups of collagen proteins can interact with wood to form a network structure. These behaviours of collagen proteins strongly suggest that a low-cost wood adhesive could be prepared by using collagen contained in leather wastes as the starting material. However, the hydrolysis of leather wastes is usually carried out via basic hydrolysis. The obtained collagen hydrolysate $(\mathrm{CH})$ usually has a low molecular weight and abundant hydrophilic groups. The direct use of these collagen hydrolysates as adhesives will have the problems of poor gluing strength and water resistance. Therefore, it is necessary to enhance the adhesive properties of collagen hydrolysate by increasing their molecular weight through crosslinking and introducing hydrophobic groups. ${ }^{10-12}$

In this work, silane coupling agents (SCA) constituted of epoxy group and alkoxy group were employed as the crosslinking agent to increase the molecular weight of $\mathrm{CH}$ extracted from leather wastes. ${ }^{13}$ Based on the reactions between SCA and collagen hydrolysate, the resultant CSH gained the desired structure, which can form stable adhesive network with high mechanical strength. Moreover, the long hydrophobic alkyl chains grafted onto CSH can provide excellent hydrophobicity for the asprepared adhesives. In this way, a low-cost and water resistant 
biomass adhesive can be obtained by using collagen extracted from leather wastes as the raw material. In the present investigation, three types of SCA with different molecular structures were employed for the preparation of $\mathrm{CSH}$ adhesives, including (3-glycidyloxypropyl)dimethoxymethylsilane (GPDMS), (3-glycidyloxypropyl)trimethoxysilane (GPTMS) and (3-glycidyloxypropyl) triethoxysilane (GPTES). Fourier transform infrared spectroscopy, ${ }^{29} \mathrm{Si}$ CP-MAS NMR spectroscopy, differential scanning calorimetry (DSC), scanning electron microscope (SEM), ANS assay and ninhydrin assay were carried out to analyze the physiochemical properties of CSH. Subsequently, the adhesive properties of CSH were systematically evaluated by using it as the adhesive to bond the wood panels, including gluing strength and water resistance.

\section{Experimental section}

\subsection{Materials}

1-Anilino-8-naphthalene sulfonate acid (ANS) and ninhydrin were purchased from Huaxia reagent Co., Ltd., (Beijing, China). GPTMS, GPTES and GPDMS were purchased from Aladdin Co., Ltd., (Shanghai, China) and used without further purification. All chemicals were analytical reagents and deionized water was used for the preparation of all solutions. Birch veneers with dimensions of $100 \mathrm{~mm}$ (length) $\times 25 \mathrm{~mm}$ (width) $\times 2 \mathrm{~mm}$ (thickness) were provided by Sichuan University (China).

\subsection{Preparation of collagen hydrolysate-SCA hybrids (CSH)}

$4.0 \mathrm{~g}$ of $\mathrm{NaOH}$ was added into $200 \mathrm{~mL}$ of water, followed by the addition of $100 \mathrm{~g}$ of chrome-containing leather waste. The mixture reacted at $95-180{ }^{\circ} \mathrm{C}(0.7 \mathrm{MPa})$ for $4-5 \mathrm{~h}$, and then treated by filtration and spray drying. The obtain material was $\mathrm{CH}$ powder. The characteristics of chrome-tanned leather waste and $\mathrm{CH}$ powder are shown in Table 1. As shown in Table 1, the chromium content is extremely low in the $\mathrm{CH}$ powder.

$\mathrm{CH}$ powder $(10 \mathrm{~g})$ was suspended in $100 \mathrm{~mL}$ of deionized water and stirred for $10 \mathrm{~min}$ at room temperature. The $\mathrm{pH}$ of the resultant mixture was adjusted to 9.0 by adding $1 \mathrm{M} \mathrm{NaOH}$ solution. Then, different ingredients of SCAs (Fig. 1) were added into the above solution, respectively, and the $\mathrm{pH}$ of the mixture was adjusted to 9.0. The system was stirred at $50{ }^{\circ} \mathrm{C}$ for $12 \mathrm{~h}$. Finally, the CSH solution was dialyzed with a dialysis membrane (Spectra/Por $\left.{ }^{\circledR}\right)$ and freeze-dried. Here, we prepared CSH with different compositions, as shown in Table 2.

Table 1 Physiochemical properties of chrome-tanned leather waste and $\mathrm{CH}$ powder

\begin{tabular}{|c|c|c|c|}
\hline \multicolumn{2}{|c|}{ Chrome-tanned leather waste } & \multicolumn{2}{|l|}{$\mathrm{CH}$ powder } \\
\hline $\mathrm{pH}$ & 4.11 & Amide nitrogen ${ }^{a_{\%}}$ & 14.85 \\
\hline Moisture\% & 55.36 & Moisture\% & 1.42 \\
\hline $\operatorname{Ash}^{a_{\%}}$ & 11.53 & $\operatorname{Ash}^{a_{\%}}$ & 14.73 \\
\hline Chrome oxide $\left(\mathrm{Cr}_{2} \mathrm{O}_{3}\right)^{a_{0}} \%$ & 1.62 & Chrome oxide $\left(\mathrm{Cr}_{2} \mathrm{O}_{3}\right)^{a_{0}} \%$ & 0.012 \\
\hline
\end{tabular}

${ }^{a}$ Moisture-free basis. (a)<smiles>CO[Si](C)(CCCOCC1CO1)OC</smiles>

(b)

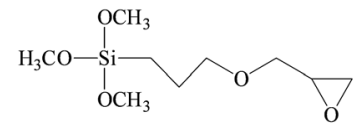

(c)

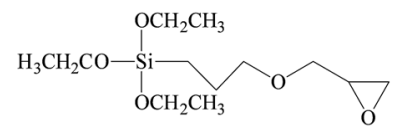

Fig. 1 Chemical structures of SCA: (a) GPDMS, (b) GPTMS, and (c) GPTES.

\subsection{Measurements of adhesive strength and water resistance}

Birch veneers were preconditioned in a chamber (model HWS150, Jinghong Co., Ltd., Shanghai) for 7 days at $23{ }^{\circ} \mathrm{C}$ with $50 \%$ relative humidity. The $\mathrm{CSH}$ slurry was brushed onto each end of birch veneer with dimensions of $152 \times 25 \mathrm{~mm}$ (length $\times$ width) until the entire area was completely wetted (ca. $5.0 \pm$ $0.1 \mathrm{mg} \mathrm{cm}^{-2} \mathrm{CSH}$ solid concentration). The preparation of specimens was described by Z. Zhong et al. ${ }^{\mathbf{1 4}}$ The variation of slurry amount on each piece was minimized by using a consistent brushing procedure. The two pieces of slurry-brushed birch veneer were allowed to rest open at room temperature for $10 \mathrm{~min}$. After assembled and pressed at $90{ }^{\circ} \mathrm{C}$ for $2 \mathrm{~h}$, the wood assembly glued with $\mathrm{CSH}$ was cooled down and cut into five 25 mm-wide specimens (glued area of $25 \times 25 \mathrm{~mm}$ ).

The required force $(\mathrm{N})$ to shear the glued wood specimens was tested with an Universal Testing Machine (model AI-7000S, GOTECH Co., Ltd., Canton) at a crosshead speed of $2 \mathrm{~mm}$ $\min ^{-1}$ (tension mode). All the reported adhesive strength data were means of five replications. Water resistance of the wood assemblies was measured in accordance with Chinese national standard (GB/T 9846.3-2004) for plywood for general use. Specifically, the preconditioned specimens were soaked in tap water at $30{ }^{\circ} \mathrm{C}$ for $2 \mathrm{~h}$ and then dried at $63{ }^{\circ} \mathrm{C}$ for $1 \mathrm{~h}$. The specimens were left at room temperature for $10 \mathrm{~min}$ and then immediately tested for wet strength. The measured date was the average of five measurements.

\subsection{Characterization}

The crosslinking extent of $\mathrm{CH}$ was determined by ninhydrin assay of primary amine group ( $\alpha$-amine) of $\mathrm{CH}$ before and after crosslinking. ${ }^{15}$ Briefly, $2 \mathrm{~mL}$ of $0.1 \mathrm{~g} \mathrm{~L}^{-1} \mathrm{CSH}$ solution (in triplicate) and $1 \mathrm{~mL}$ of $0.5 \%(\mathrm{w} / \mathrm{v})$ ninhydrin solution in $0.5 \mathrm{~mol} \mathrm{~L}^{-1}$ phosphate buffer ( $\mathrm{pH}$ 6.0) was added into the colorimetric

Table 2 The reactant molar ratio of SCA over $\mathrm{CH}$

\begin{tabular}{lccccc}
\hline Reactants & $1 \#$ & $2 \#$ & $3 \#$ & $4 \#$ & $5 \#$ \\
\hline CH & 1.0 & 1.0 & 1.0 & 1.0 & 1.0 \\
GPDMS & 0.1 & 0.5 & 1.0 & 1.5 & 2.0 \\
GPTMS & 0.1 & 0.5 & 1.0 & 1.5 & 2.0 \\
GPTES & 0.1 & 0.5 & 1.0 & 1.5 & 2.0
\end{tabular}


tubes. Then, the resultant ninhydrin-containing suspension was heated in a covered boiling water bath for $20 \mathrm{~min}$, followed by cooling below $30{ }^{\circ} \mathrm{C}$ in a cold water bath. The cooled suspension was diluted with $7 \mathrm{~mL}$ of $45 \%$ ethanol/water solution (v/v) and the optical absorbance of the supernatant solution was recorded at $570 \mathrm{~nm}$. Values are means of three measurements. Crosslinking degree was calculated as below:

$$
\text { Crosslinking degree }=\frac{\mathrm{CH}_{0}-\mathrm{CH}_{1}}{\mathrm{CH}_{0}} \times 100 \%
$$

where $\mathrm{CH}_{0}$ and $\mathrm{CH}_{1}$ are the number of primary amine group $(\alpha$ amine) of $\mathrm{CH}$ before and after crosslinking with SCA, respectively.

Surface hydrophobicity of $\mathrm{CSH}$ was determined by using the 1-anilino-8-naphthalene sulfonate (ANS) as a fluorescence probe according to the literature. ${ }^{16}$ Accordingly, the $\mathrm{CSH}$ samples with concentration ranging from 0.5 to $2.5 \mathrm{~g} \mathrm{~L}^{-1}$ were prepared by using $10 \mathrm{mM}$ phosphate buffer $(\mathrm{pH}$ 7.0) as the solvent. $100 \mu \mathrm{L}$ of the ANS (8 mM ANS in $10 \mathrm{mM}$ phosphate buffer) was added in $10 \mathrm{~mL}$ of $\mathrm{CSH}$ solution. The ANS-CSH conjugates were excited at $380 \mathrm{~nm}$ and the relative fluorescence intensities were measured at $450 \mathrm{~nm}$ in a fluorescence spectrophotometer (model G9800A, Agilent Technologies Co., Ltd., USA) with $5 \mathrm{~nm}$ slit widths. The slope $\left(S_{0}\right)$ of the plot of fluorescence intensity (arbitrary units) versus $\mathrm{CSH}$ concentration ( $\mathrm{g}$ $\mathrm{L}^{-1}$ ) was calculated by linear regression and was used as the index of the $\mathrm{CSH}$ hydrophobicity.

FT-IR spectroscopic data were collected in the region of 4000-400 $\mathrm{cm}^{-1}$ with an FT-IR spectrometer (model IS10, Thermo Fisher Scientific Co., Ltd., USA). The fracture surface morphologies of birch were observed by a scanning electron microscope (model Phenom Pro, PhenomChina Co., Ltd., Shanghai) operating at $10 \mathrm{kV}$.

Solid-state ${ }^{29} \mathrm{Si}$ CP-MAS NMR measurements were carried out using solid NMR spectrometer (model AVANCE III $500 \mathrm{MHz}$, Bruker Co., Ltd., Switzerland) operating at $99.35 \mathrm{MHz}$ and 11.746 $\mathrm{T}$ with $10 \mathrm{~s}$ recycle delays. Sample spinning rate was approximately $4-4.5 \mathrm{kHz}$. The samples were placed in $7 \mathrm{~mm}$ $\mathrm{ZrO}_{2}$ rotors. A $39 \mathrm{kHz}$ spectral width was used. The ${ }^{29} \mathrm{Si}$ scale was calibrated with the signal from the external standard polydimethylsilane (PDMS, $\delta=-34 \mathrm{ppm})$. $\mathrm{T}_{i}$ corresponds to $\mathrm{R}^{\prime}-\mathrm{Si}(-$ $\mathrm{OSi})_{i}-\mathrm{OR}_{(3-i)}$, a tri-functional silicate. Thus, four $\mathrm{T}$ types can be presented, namely $\mathrm{T}_{0}, \mathrm{~T}_{1}, \mathrm{~T}_{2}$ and $\mathrm{T}_{3}$, as sketched in Fig. 2 . These peaks have the typical chemical shift ranges: $\mathrm{T}_{0}:-37$ to $-39 \mathrm{ppm}, \mathrm{T}_{1}:-46$ to $-48 \mathrm{ppm}, \mathrm{T}_{2}:-53$ to $-57 \mathrm{ppm}$, and $\mathrm{T}_{3}:-61$ to $-66 \mathrm{ppm}$. For $\mathrm{R}^{\prime}-\mathrm{Si}(-\mathrm{OSi})_{i}-\mathrm{OR}_{(2-i)}$, a di-functional silicate, three ' $D$ ' peaks can be presented, namely $D_{0}, D_{1}, D_{2}$, as sketched in Fig. 2, with the following typical chemical shift ranges: $D_{0}:-3$ to $-5 \mathrm{ppm}, \mathrm{D}_{1}$ : -8 to $-12 \mathrm{ppm}$, and $\mathrm{D}_{2}:-13$ to $-19 \mathrm{ppm}^{17,18}$

\section{Results and discussion}

\subsection{Preparation and characterization of CH-SCA hybrids} (CSH)

We prepared three types of $\mathrm{CSH}$ adhesives, and their crosslinking degrees were determined by ninhydrin assay of uncrosslinked primary amine groups ( $\alpha$-amine) of $\mathrm{CH}$ since the

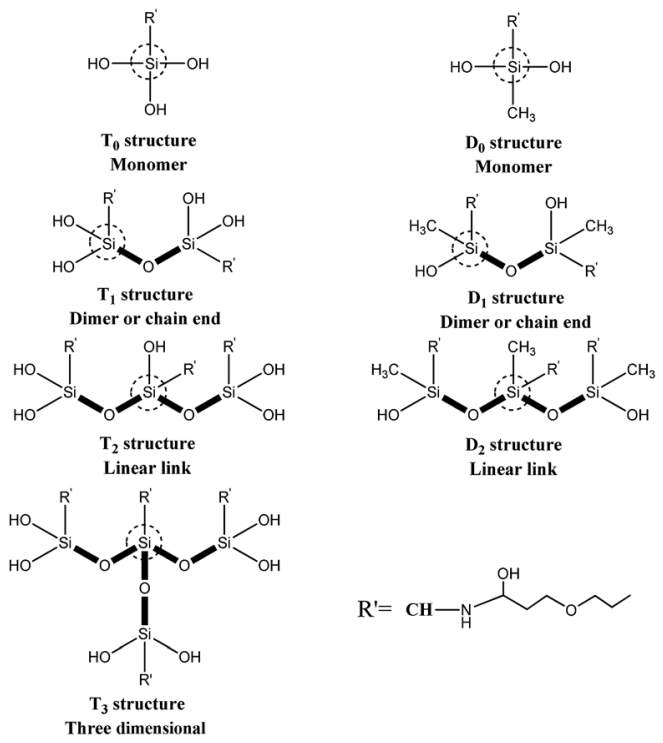

Fig. 2 Schematic illustration showing the molecular structures of $T_{i}$ and $\mathrm{D}_{i}$ units.

preparation of $\mathrm{CH}-\mathrm{SCA}$ was mainly based on the reaction between epoxy group of SCA and the $\alpha$-amine of $\mathrm{CH} .{ }^{19}$ As shown in Fig. 3a, when the molar ratio of SCA (GPDMS, GPTMS and GPTES) to $\mathrm{CH}$ is increased from 0 to 2, the crosslinking degree is increased accordingly, suggesting the successful cross-linkage between SCA and $\mathrm{CH}$. The crosslinking degrees of GPDMS$\mathrm{CH}, \mathrm{GPTMS}-\mathrm{CH}$ and GPTES-CH were determined to be $43 \%$, $37 \%$ and $27 \%$, respectively. It is noted that the crosslinking efficiency of SCA to $\mathrm{CH}$ obeys the following order: GPDMS > GPTMS > GPTES. These results suggest that the use of SCA with smaller steric hindrance is beneficial for the crosslinking of $\mathrm{CH}$.


Fig. 3 (a) Crosslinking extent of $\mathrm{CH}$ as the function of molar ratio between SCA and $\mathrm{CH}$. (b) FT-IR spectra of (1) $\mathrm{CH}$, (2) GPDMS-CH, (3) GPTES-CH and (4) GPTMS-CH. (c) Solid-state ${ }^{29} \mathrm{Si} C P-M A S ~ N M R$ spectra of GPDMS-CH, GPTMS-CH and GPTES-CH. (d) Surface hydrophobicity $\left(S_{0}\right)$ values of collagen hydrolysate with the molar ratio of SCA over $\mathrm{CH}$ in the range of 0.1-2.0 in phosphate buffer. 
Fig. 3b shows the FT-IR transmittance spectra of $\mathrm{CH}$, GPDMS-CH, GPTMS-CH and GPTES-CH, respectively. The FT-IR of $\mathrm{CH}$ shows the typical bands of amide I, amide II and amide III of collagen at $1600-1700 \mathrm{~cm}^{-1}, 1500-1550 \mathrm{~cm}^{-1}$ and 1200-1300 $\mathrm{cm}^{-1}$, respectively. ${ }^{20,21}$ The peak at 3500-3300 $\mathrm{cm}^{-1}$ arises from the stretching of amine groups. After crosslinking with SCA, the broad band between 1000 and 1200 $\mathrm{cm}^{-1}$ was caused by stretching of $\mathrm{C}-\mathrm{O}$ and $\mathrm{Si}-\mathrm{O}$ bonds as shown in the spectra of Fig. $3 b(2-4) .{ }^{22,23}$ Moreover, a characteristic band is started to appear at $910 \mathrm{~cm}^{-1}$ in Fig. $3 \mathrm{~b}(2-4)$, corresponding to the stretching vibration of $\mathrm{Si}-\mathrm{O}-\mathrm{H} .{ }^{24}$ These new formed bonds indicate that the $\mathrm{CH}$ was successfully cross-linked with SCA.

The ${ }^{29} \mathrm{Si}$ solid-state NMR spectra of the $\mathrm{CH}$ cross-linked with GPDMS, GPTMS and GPTES are shown in Fig. 3c, respectively. The chemical shift and relative peak area (\%) of each $\mathrm{T}_{i}$ and $\mathrm{D}_{i}$ units are shown in Table S1. $\dagger$ The NMR patterns of GPTMS-CH and GPTES-CH show no significant difference in the chemical shift from $-40 \mathrm{ppm}$ to $-80 \mathrm{ppm}$. The quantitative analysis of GPTMS-CH spectra shows that the GPTMS-CH is composed of $5.15 \% \mathrm{~T}_{1}$ units, $26.02 \% \mathrm{~T}_{2}$ units and $68.83 \% \mathrm{~T}_{3}$ units. As for GPTES-CH, it composed of $7.37 \% \mathrm{~T}_{1}$ units, $21.47 \% \mathrm{~T}_{2}$ units and $71.16 \% \mathrm{~T}_{3}$ units. Both GPTMS-CH and GPTES-CH have a high proportion of $\mathrm{T}_{3}$ units, which indicates that the main content of those adhesive is three dimensional oligomeric network, which is formed from the hydrolysis and condensation of tri-alkoxy. ${ }^{25}$ The quantitative analysis of GPDMS-CH shows that GPDMS$\mathrm{CH}$ is composed of $30.55 \% \mathrm{D}_{1}$ units and $69.45 \% \mathrm{D}_{2}$ units. These results suggest that GPDMS-CH mainly consists of linear runs of $\mathrm{Si}-\mathrm{O}-\mathrm{Si}$ groups, which is formed from the hydrolysis and condensation of di-alkoxy. ${ }^{26}$

We further measured the surface hydrophobicity of $\mathrm{CSH}$. With the molar ratio of SCA over $\mathrm{CH}\left(m_{\mathrm{SCA}} / m_{\mathrm{CH}}\right)$ increased from 0.1 to 2.0 , the surface hydrophobicity of GPDMS-CH, GPTMS-CH and GPTES-CH was determined to be 51-91, 51366, 51-274, respectively (Fig. 3d). It is apparent that increasing the dosage of SCA improves the surface
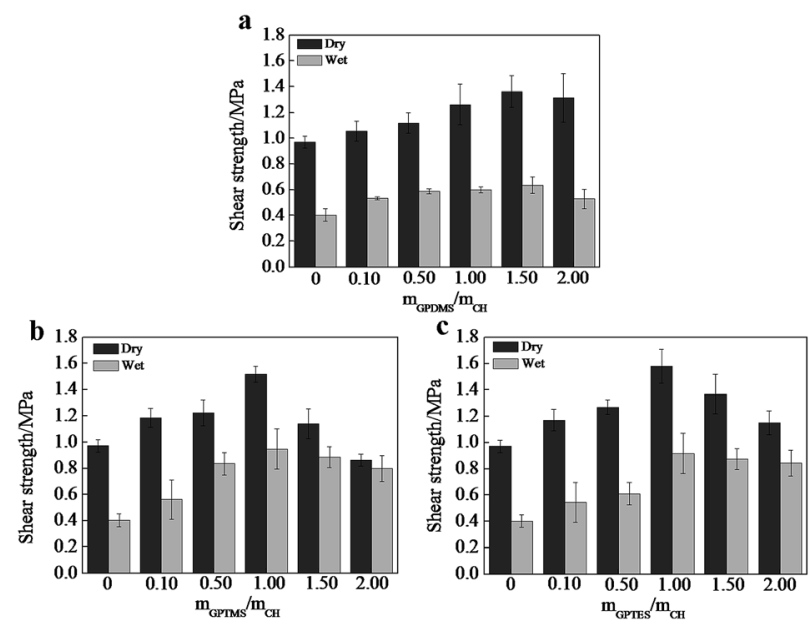

Fig. 4 Influences of the molar ratio of (a) GPDMS/CH, (b) GPTMS/CH and (c) GPTES/CH on shear strengths. hydrophobicity of $\mathrm{CSH}$, owing to the increased number of hydrophobic alkyl chains. We noted that along with the increase of $m_{\mathrm{SCA}} / m_{\mathrm{CH}}$, the hydrophobicity growth trend of GPTMS-CH and GPTES-CH are significantly faster than that of GPDMS-CH. Based on above analysis of ${ }^{29} \mathrm{Si}$ solid-state NMR spectra, the structure of GPTMS-CH and GPTES-CH features to a dimensional network, which could provide more effective hydrophobic protection to $\mathrm{CH}$ than that of linearstructured GPDMS-CH, thus showing improved water resistance.

\subsection{Adhesive properties of birch wood bonded by CSH adhesives}

Adhesive strength is a critical factor to evaluate the property of adhesives, we thus tested the shear strength of CSH glued wood specimen. As shown in Fig. 4, the optimized dry shear strength of CSH glued wood specimens can be as high as 1.36, 1.51 and $1.57 \mathrm{MPa}$, respectively, which is substantially higher than that (0.91 MPa) of $\mathrm{CH}$ glued wood specimens. Fig. $5 \mathrm{a}$ is the SEM image showing the surface microstructure of native birch veneer without treated by adhesive, which features to a strip-like rough surface. As for the fractured wood specimens glued with $\mathrm{CH}$, the surface on the fractured area showed very smooth surface, which is due to the coverage and filling of $\mathrm{CH}$ over the rough surface of native birch veneer. Similar phenomenon was also observed on the fractured surfaces of $\mathrm{CSH}$-glued wood species, where abundant adhesives reside on the fracture surface, revealing that the three types of $\mathrm{CSH}$ adhesive have excellent dry strength to birch wood. We know that there are abundant hydroxyls on birch wood, which can form hydrogen bond or covalent bond with the silanol groups of $\mathrm{CSH}$, thus improving the adhesive strength between wood and $\mathrm{CSH}$. On the other hand, the network structure of $\mathrm{CSH}$ derived from the condensation of silanol in adhesive can also help to enhance the adhesive strength. These factors together bring us the excellent dry adhesive strength for $\mathrm{CSH}$-glued wood species.

As for wood adhesives, the water resistance is also an important property. Table $\mathrm{S} 2 \uparrow$ shows the wood failure results of

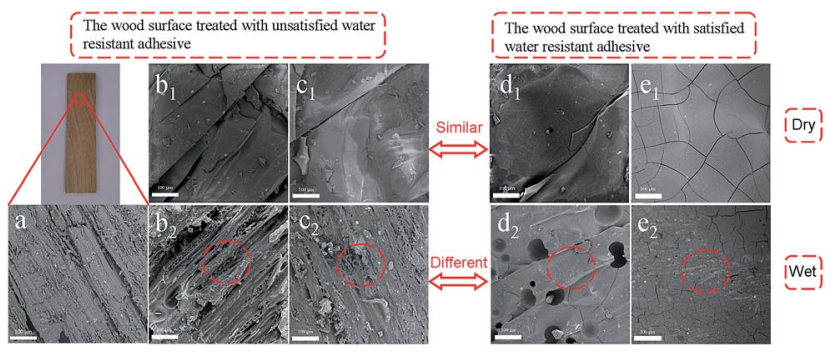

Fig. 5 Scanning electron micrograph of (a) birch surface without adhesives and fracture surfaces of $\left(b_{1}\right.$ and $\left.b_{2}\right) \mathrm{CH},\left(c_{1}\right.$ and $\left.c_{2}\right)$ GPDMS$\mathrm{CH},\left(\mathrm{d}_{1}\right.$ and $\left.\mathrm{d}_{2}\right)$ GPTMS- $\mathrm{CH}$ and $\left(\mathrm{e}_{1}\right.$ and $\left.\mathrm{e}_{2}\right)$ GPTES- $\mathrm{CH}$ treated birch surfaces. $\left(b_{1}\right)-\left(e_{1}\right)$ represent the birch specimens fractured before soaking in water, $\left(b_{2}\right)-\left(e_{2}\right)$ represent the birch specimens fractured after soaking in water. Horizontal bars represent $100 \mu \mathrm{m}$ for $\times 500$ magnifications. 
the plywood panels bonded with different $\mathrm{CH}$-based adhesives in soak tests. The plywood panels bonded with $\mathrm{CH}$ adhesive containing SCA have less failed specimens than those bonded without SCA. Moreover, no specimen is failed in the soak test when the molar ratio of SCA over $\mathrm{CH}$ is more than 1.0. Apparently, the use of GPDMS, GPTMS and GPTES improves the water resistance of the bonded plywood panels. As shown in Fig. 4, the wet shear strength of $\mathrm{CH}$ glued wood specimen is $0.51 \mathrm{MPa}$, substantially lower than its dry shear strength. Based on SEM observation, we found that the fractured surface of $\mathrm{CH}$ glued wood specimens has very limited $\mathrm{CH}$ covered, which is similar to the morphology of un-glued birch veneer. Obviously, $\mathrm{CH}$ glued wood specimens has quite poor water resistance due to its weak interactions with the wood surface in the presence of water. The optimized wet shear strength of CSH glued wood specimens are $0.63,0.95$ and $0.92 \mathrm{MPa}$, respectively. In spite that the wet shear strength of CSH glued wood specimens are lower than those of corresponding dry shear strength, the wet adhesive strengths of GPTMS-CH and GPTES-CH glued wood specimens are still high enough to meet the requirement of Chinese national standard (GB/T 9846.3-2004, 0.7 MPa). As shown in Fig. $5 c_{2}$, the fractured surface of GPDMS-CH glued wood specimen is still very rough, and features to the typical strip-like microstructure, similar to the surface microstructure of native birch veneer. In contrast, the fractured surfaces of GPTMS-CH and GPTES-CH glued wood specimens are still fully covered by the used adhesives (Fig. $5 \mathrm{~d}_{2}$ and $\mathrm{e}_{2}$ ). All these results suggest that the use of GPTMS-CH and GPTES-CH as adhesives can provide pretty good wet adhesive strength owing to their strong interactions with wood. It is reasoned that GPDMS mainly forms in linear link in the adhesives, which is not effect enough to cover and protect the hydrophilic surface of wood, thus leading to poor wet shear strength. For GPTMS and GPTES, they mainly forms three dimensional networks in the adhesives and a large number of crosslinking structures might be formed between silanol and the hydroxyls of wood surface, producing much better hydrophobicity.

It is noted that the dry and wet shear strength both decline as further increasing the dosage of SCA beyond the optimized value. This phenomena can be attributed to the formation of abundant covalent bonds, which causes the reduction of wetting ability and the gel of $\mathrm{CSH}$ with poor flow ability, hindering the physical attraction and chemical bonding with wood. ${ }^{27,28}$

\section{Conclusions}

In summary, a novel biomass adhesive was facilely prepared using collagen hydrolysate extracted from leather wastes as the raw material. The as-prepared low-cost adhesive exhibited a properly crosslinked three dimensional structure network, which allowed good interactions with wood, thus showing pretty good adhesive strength and water resistance. Our experimental results suggest that the collagen hydrolysate extracted from leather wastes has a great potential to be used as low cost and high effective adhesive in wood composite industry.

\section{Acknowledgements}

The research was financially supported by National High Technology R\&D program (2011AA06A108). Jianfei Zhou and Teng $\mathrm{Xu}$ have equal contribution to this work.

\section{References}

1 J. Kanagaraj, K. C. Velappan, B. N. K. Chandra and S. Sadulla, J. Sci. Ind. Res., 2006, 65, 541-548.

2 T. Basegio, C. Haas, A. Pokorny, A. M. Bernardes and C. P. Bergmann, J. Hazard. Mater., 2006, 137, 1156-1164.

3 B. Ocak, A. Aslan and G. Gulumser, J. Am. Leather Chem. Assoc., 2011, 106, 232-238.

4 A. Malek, M. Hachemi and V. Didier, J. Hazard. Mater., 2009, 170, 156-162.

5 K. Kolomazník, M. Adámek, I. Andel and M. Uhlirova, J. Hazard. Mater., 2008, 160, 514-520.

6 Q. J. Lin, N. R. Chen, L. P. Bian and M. Z. Fan, Int. J. Adhes. Adhes., 2012, 34, 11-16.

7 N. S. Hettiarachchy, U. Kalapathy and D. J. Myers, J. Am. Oil Chem. Soc., 1995, 72, 1461-1464.

8 K. Li, X. Geng, J. Simonsen and J. Karchesy, Int. J. Adhes. Adhes., 2004, 24, 327-333.

9 M. A. Khan, S. M. Ashraf and V. P. Malhotra, Int. J. Adhes. Adhes., 2004, 24, 485-493.

10 G. Y. Qi, N. B. Li, D. H. Wang and X. S. Sun, Ind. Crops Prod., 2013, 46, 165-172.

11 D. G. Liu, H. H. Chen, P. R. Chang, Q. L. Wu, K. F. Li and L. T. Guan, Bioresour. Technol., 2010, 101, 6235-6241.

12 L. Halasz, O. Vorster, A. Pizzi and J. V. Alphen, J. Appl. Polym. Sci., 2000, 75, 1296-1302.

13 T. C. Tonda, P. Gentile, S. Saracino, V. Chiono, V. K. Nandagiri, G. Muzio, R. A. Canuto and G. Ciardelli, Int. J. Biol. Macromol., 2011, 49, 700-706.

14 Z. K. Zhong, X. S. Sun, X. H. Fang and J. A. Ratto, Int. J. Adhes. Adhes., 2002, 22, 267-272.

15 S. Prochazkova, K. M. Vårum and K. Ostgaard, Carbohydr. Polym., 1999, 38, 115-122.

16 Y. H. You, Y. H. Zeng and Y. S. Liu, J. Soc. Leather Technol. Chem., 2014, 98, 69-75.

17 M. P. J. Peeters, W. J. J. Wakelkamp and A. P. M. Kentgens, J. Non-Cryst. Solids, 1995, 189, 77-89.

18 T. M. Alam, R. A. Assink and D. A. Loy, Chem. Mater., 1996, 8, 2366-2374.

19 Y. Shirosaki, K. Tsuru, S. Hayakawa, A. Osaka, M. A. Lopes, J. D. Santos, M. A. Costa and M. H. Fernandes, Acta Biomater., 2009, 5, 346-355.

20 M. C. Chang and J. Tanaka, Biomaterials, 2002, 23, 48114818.

21 N. P. Camacho, P. West, P. A. Torzilli and R. Mendelsohn, Biopolymers, 2001, 62, 1-8.

22 M. Bengtsson and K. Oksman, Composites, Part A, 2006, 37, 752-765.

23 J. W. Gu, J. Dang, W. C. Geng and Q. Y. Zhang, Fibers Polym., 2012, 13, 979-984. 
24 M. Pantoja, B. B. Díaz, F. Velasco, J. Abenojar and J. C. R. Del, Appl. Surf. Sci., 2009, 255, 6386-6390.

25 M. C. B. Salon, G. Gerbaud, M. Abdelmouleh, C. Bruzzese, S. Boufi and M. N. Belgacem, Magn. Reson. Chem., 2007, 45, 473-483.
26 S. K. Young, W. L. Jarrett and K. A. Mauritz, Polymer, 2002, 43, 2311-2320.

27 Y. Wang, X. Mo, X. S. Sun and D. H. Wang, J. Appl. Polym. Sci., 2007, 104, 130-136.

28 M. Gindl, G. Sinn, W. Gindl, A. Reiterer and S. Tschegg, Colloids Surf., A, 2001, 181, 279-287. 